\title{
Long-term metabolic control in recipients of combined pancreas and kidney transplants
}

\author{
H. Holdaas ${ }^{1}$, I. B. Brekke ${ }^{2}$, A. Hartmann ${ }^{1}$, Ø. H. Bentdal ${ }^{2}$, T. Ganes ${ }^{3}$, A. Gjellestad ${ }^{1}$, P. Fauchald ${ }^{1}$, K. J. Berg ${ }^{1}$, \\ O. Djøseland ${ }^{1}$, J. Jervell ${ }^{1}$ and A. Flatmark ${ }^{2}$ \\ Departments of ${ }^{1}$ Internal Medicine, ${ }^{2}$ Surgery and ${ }^{3}$ Neurology, The National Hospital, University of Oslo, Norway
}

Summary. Metabolic glucose control was followed in 36 patients at 12-month intervals for up to 5 years after a successful combined kidney and segmental duct-occluded pancreas transplantation. All recipients had normal blood glucose levels at each examination. $\mathrm{HbA1}$ values, intravenous glucose tolerance test, $\mathrm{C}$-peptide levels and C-peptide responses to glucagon stimulation were also, on average, within the normal range. Several individual patients had, however, abnormal values for these parameters. At most $46 \%$ had abnormal values for $\mathrm{HbA1}$ and intravenous glucose tolerance test, up to $13 \%$ showed low C-peptide values and up to $46 \%$ of the stimulated $\mathrm{C}$-peptide responses were inadequate at the different intervals. These parameters did not deteriorate with time. This was true both for the whole group of patients as well as for the 6 patients with a 5-year observation time evaluated separately. Despite these abnormalities

in glucose metabolism, all patients remained normoglycaemic without need for exogenous insulin up to 5 years after transplantation. The long-term ability of duct-occluded segmental pancreatic grafts to preserve euglycaemia therefore seems to remain intact at least for 5 years.

Key words: Combined Pancreas-KidneyTransplantation Glucose-Metabolism Long-term

\section{Introduction}

A successful pancreas transplantation implies independency of insulin injections for the diabetic patient. This undoubtedly improves the diabetic recipient's quality of life (Nakache et al. 1989). A drawback is that insulin- independency is substituted for by potentially lifelong immunosuppressive therapy. However, in combined renal and pancreas transplantation the renal grafting per se necessitates immunosuppressive therapy. Our policy has therefore been to offer uraemic diabetic patients a combined pancreas and kidney transplantation provided no living donor is available.

The primary aim of a successful pancreas transplantation is to normalize the glucose metabolism and to reverse or halt the secondary complications of diabetes. Although normoglycaemia is obtained in diabetic patients after a successfully transplanted pancreas, not all insulin-independent recipients obtain a complete normalization of glucose metabolism (Groth 1988; Landgraf 1989; Holdaas 1990; Nordén 1990).

At our centre the segmental duct-occlusion technique with neoprene has been the preferred technique from 1983 to 1988 . The purpose of this study was to evaluate the long-term effect on glucose metabolism of combined renal and pancreas transplantation in diabetic recipients with a functioning pancreas graft up to 5 years after transplantation.

\section{Subjects and methods}

Patients. From June 1983 to February 1987, 36 uraemic diabetic patients received combined kidney and pancreatic grafts. Twenty-two patients were available for evaluation at 1 year, 16 at 2 years, 13 at 3 years, 10 at 4 years and 6 at 5 years. Successful pancreas transplantation was defined as independency of insulin therapy, consequently patients with partially functioning pancreatic grafts were excluded.

Surgery. The surgical procedure has previously been described (Dubernard et al 1978).

Immunosuppression The immunosuppressive regimen consisted of 
Table 1. Patient data, medication and renal function from 1 to 5 years after combined pancreas and kidney transplantation.

\begin{tabular}{|c|c|c|c|c|c|}
\hline Years from transplantation & 1 & 2 & 3 & 4 & 5 \\
\hline Number of patients & 22 & 16 & 13 & 10 & 6 \\
\hline Age (years) & $40 \pm 2$ & $40 \pm 2$ & $43 \pm 2$ & $44 \pm 2$ & $47 \pm 2$ \\
\hline Duration of diabetes (years) & $26 \pm 2$ & $29 \pm 2$ & $31 \pm 2$ & $33 \pm 3$ & $34 \pm 3$ \\
\hline Prednisolone (mg/day) & $10 \pm 1$ & $9 \pm 1$ & $10 \pm 1$ & $10 \pm 0$ & $10 \pm 0$ \\
\hline Cyclosporine A (mg/day) & $350 \pm 130$ & $315 \pm 110$ & $315 \pm 20$ & $300 \pm 20$ & $280 \pm 20$ \\
\hline Creatinine $(\mu \mathrm{mol} / \mathrm{l})$ & $142 \pm 8$ & $135 \pm 10$ & $156 \pm 18$ & $168 \pm 30$ & $154 \pm 21$ \\
\hline
\end{tabular}

The data are expressed as means \pm SEM

cyclosporine $A$ and prednisolone in the first 10 patients; in the remaining patients azathioprine was added. Rejection episodes were treated with i.v. boluses of methylprednisolone and/or polyclonal antilymphocyte globulin.

Metabolic evaluation was assessed by the following parameters: Fasting blood glucose; blood glucose was measured by the hexolinase method. Intravenous glucose tolerance test (IVGT); IVGT ( $25 \mathrm{~g}$ of glucose) was assessed by the diminuation rate of blood glucose expressed as a $\mathrm{K}$ value (Lundbaek 1962). Glycosylated haemoglobin A1 (HbA1); HbA1 was measured by a microcolumn technique (Bio-Rad, Munich, FRG). Normal range is 6-8\%. Basal and stimulated C-peptide; C-peptide was determined by a commercial radioimmunoassay method (Novo Cpeptide kit, Bagsvaerd, Denmark). Stimulation test for C-peptide response was performed by giving $1 \mathrm{mg}$ of glucagon intravenously (Sarlund et al 1987).

\section{Results}

All patients with a functioning graft were examined every
12 months after transplantation. The patient characteristics, medication and renal function 1, 2, 3, 4 and 5 years after transplantation are shown in Table 1. The patients had suffered from diabetes mellitus for about 30 years before transplantation. The serum creatinine levels were stable during the whole observation period and were within the same range as for diabetic patient with a kidney transplant only.

The data assessing glucose metabolism are summarized in Table 2. The percentage of patients within the normal range for the various parameters are also shown in the table. None of the mean values of the metabolic parameters for the overall material showed any tendency to decline with time. Fasting blood glucose levels were normal in all patients at all intervals. The mean $\mathrm{HbA1}$ values were normal or at the upper range of normal. However, the percentage of individual patients within normal range for $\mathrm{HbA1}$ varied.

Table 2. Parameters assessing metabolic glucose control from 1 to 5 years after combined pancreas and kidney transplantation.

\begin{tabular}{llllll}
\hline Years from transplantation & 1 & 2 & 3 & 4 & 5 \\
\hline Blood glucose (mmol/l) & $5.2 \pm 0.1$ & $4.9 \pm 0.2$ & $5.1 \pm 0.2$ & $4.6 \pm 0.2$ & $5.0 \pm 0.2$ \\
Within normal range, \% & 100 & 100 & 100 & 100 & 100 \\
HbA1, \% & $8.0 \pm 0.2$ & $8.0 \pm 0.3$ & $8.0 \pm 0.3$ & $7.7 \pm 0.2$ & $7.8 \pm 0.3$ \\
Within normal range, \% & 54 & 63 & 77 & 80 & 83 \\
IVGTT, $K$-value & $1.3 \pm 0.2$ & $1.2 \pm 0.1$ & $1.2 \pm 0.1$ & $1.2 \pm 0.1$ & $1.3 \pm 0.2$ \\
Within normal range, \% & 54 & 63 & 69 & 80 & 83 \\
C-peptide (nmol/l) & $0.8 \pm 0.1$ & $0.7 \pm 0.1$ & $0.8 \pm 0.2$ & $0.7 \pm 0.1$ & $0.8 \pm 0.2$ \\
Within normal range, \% & 89 & 88 & 77 & 89 & 100 \\
C-peptide response (nmol/) & $0.5 \pm 0.1$ & $0.4 \pm 0.1$ & $0.4 \pm 0.1$ & $0.4 \pm 0.1$ & $0.7 \pm 0.1$ \\
Within normal range, \% & 59 & 56 & 54 & 56 & 83 \\
\hline
\end{tabular}

HbA1 = glucosylated haemoglobin A1; IVGTT = Intravenous glucose tolerance test $;$-peptide response $=$ Increase in C-peptide concentration in response to $1 \mathrm{mg}$ of i.v. glucagon. Data are expresssed as means \pm SEM 
Although the mean $\mathrm{K}$-values were consistently stable for all examinations throughout the study, individual analysis revealed that several patients had abnormal $\mathrm{K}$-values at one or several of the yearly examinations. The normal range for C-peptide at our laboratory is $0.3-1.0 \mathrm{nmol} / \mathrm{l}$. Basal C-peptide levels are at, or slightly above, normal values. The normal response range for stimulated $\mathrm{C}$ peptide in response to glucagon is above $0.4 \mathrm{nmol} / \mathrm{l}$. A large proportion of the patients exhibited subnormal values.

\section{Discussion}

This study demonstrates that the duct-occlusion segmental technique for pancreas transplantation is successful in achieving long-term normoglycaemia without exogenous insulin therapy in diabetic patients. However, the study also shows that normoglycaemia does not necessarily indicate normalization of all parameters used to assess glucose homeostasis. A dissociation between normoglycaemia and other indicators used to characterize glucose metabolism has previously been demonstrated (Groth et al. 1988; Landgraf et al 1989; Robertson et al. 1989; Nordén et al. 1990). The results from our study extend these observations showing that even in patients with abnormal $\mathrm{HbA1}$ values, glucose disappearance curves and $\mathrm{C}$-peptide responses still are normoglycaemic and without any need for exogenous insulin 5 years after transplantation. The inadequacy of a complete normalization of glucose metabolism seems to be similar whether the exocrine secretion of the pancreas is diverted to the intestine (Groth et al. 1988) or to the bladder (Robertson et al. 1989; Nordén et al. 1990) or as in our study with occlusion of the ductal system with neoprene. A more probable explanation is that all these techniques place the allografted pancreas heterotopically leading to systemic rather than portal release of insulin. Moreover, pancreas transplantation necessarily implies a denervation of the organ. Autonomic nerve stimulation is regarded as essential for proper endocrine pancreas function (Garber et al. 1976). Recipients of allografts are also subjected to continuous immunosuppression with prednisolone and cyclosporine $\mathrm{A}$, and these drugs adversely affect islet cell function and peripheral insulin sensitivity (Gunnarson et al. 1983).

Segmental transplantation of the pancreas with occlusion of the ductal system with neoprene abolishes the exocrine function of the graft. A continuous concern has been whether the atrophy of the exocrine pancreas and the subsequent fibrosis of the transplanted pancreas adversely affects the endocrine function of the graft (Robertson et al. 1989). One would expect a gradual deterioration in metabolic glucose control with time if the fibrosis also replaced islet cells. However, our study demonstrates that duct-occluded pancreatic grafts preserve their capacity to regulate glucose metabolism unchanged at near normal levels up to 5 years following transplantation. This finding is consistent whether the overall material is evaluated as in Table 2, or if the six patients with functioning grafts for 5 years are analysed separately. Our study indicates that preservation of the exocrine pancreatic tissue is not a prerequisite for the long-term endocrine function of pancreatic transplants.

\section{References}

Dubernard JM, Traeger J, Neyra P, Touraine I, Tranchant D, BlancBrunat N (1978) New method of preparation of a segmental pancreatic graft for transplantation: trials in dogs and in man. Surgery 84: 634-639

Garber AJ, Cryer PE, Santiago JV, Haymond MW, Pagliana AS, Kipnis DM (1976) The role of adrenergic mechanisms in the substrate and hormonal response to insulin-induced hypoglycemia in man. J Clin Invest 58: 7-15

Groth CG, Tydén G, Brattström C, Boman SO, Östman J (1988) Pancreatic transplantation for diabetes mellitus: The Stockholm experience. Transpl Proc XX; [suppl] 1: 862-865

Gunnarsson R, Klintmalm G, Lundgren G, Wilczek H, Östman J, Groth CG (1986) Deterioration in glucose metabolism in pancreatic transplant recipients given cyclosporine. Lancet 2: 571-572

Holdaas H, Brekke IB, Hartmann A, Fauchald P, Berg KJ, Søodal G, Jervell J, Flatmark, A (1990) Metabolic control in recipients of ductoccluded segmental pancreatic grafts: A four-year follow-up. Transpl Proc 22: 655-656

Landgraf R, Nusser J, Müller W, Landgraf-Leurs MMC, Thurau S, Ulbig M, Kampik A, Lachenmayr B, Hillebrand G, Schleibner S, Illner WD, Abendroth D, Land W (1989) Fate of late complications in type I diabetic patients after successful pancreas-kidney transplantation. Diabetes 38; [suppl] 1: 33-37

Lundbaek K (1962). Intravenous glucose tolerance as a tool in definition and diagnosis of diabetes mellitus. Brit Med J 2: 1507-1511

Nakache R, Tydén G, Groth, CG (1989) Quality of life in diabetic patients after combined pancreas-kidney or kidney transplantation. Diabetes 38: [suppl] 1: 40-42

Nordén G, Nyborg G, Hedman L, Olausson M, Frisk B (1990) Transplantation in patients with diabetic nephropathy. Transpl Int 3: 234-237

Robertson RP, Abid M, Sutherland DER, Diem P (1989) Glucose homeostasis and insulin secretion in human recipients of pancreas transplantation. Diabetes 38; [suppl] 1: 97-98

Sarlund H, Siitonen O, Laakso M, Pyörala K (1987) Repeatibility of Cpeptide response in glucagon stimulation test. Acta Endocrinologica 114: $515-518$

Dr.H. Holdaas

Department of Medicine B

Rikshospitalet, University of Oslo

0027 Oslo 1, Norway 